\title{
CUSTOS DE PRODUÇÃO DE FÊMEAS BOVINAS LEITEIRAS DO NASCIMENTO AO PRIMEIRO PARTO
}

\author{
GLAuber SANTOS ${ }^{1}$, MARCOS AurÉLIO LOPES $^{2}$ \\ ${ }^{1}$ Pós-Graduando da Universidade de São Paulo, Piracicaba, SP, Brasil; \\ ${ }^{2}$ Professor Doutor da Universidade Federal de Lavras, Lavras, MG, Brasil. malopes@dmv.ufla.br
}

\begin{abstract}
Objetivou-se apresentar o custo de produção de fêmeas bovinas leiteiras Holandesa e mestiças (Holandês-Gir), nas fases de cria e recria e, ainda, identificar os componentes que exerceram maior representatividade sobre os custos finais da atividade. Nos dois grupamentos genéticos, a cria e a recria compreenderam ao período do nascimento ao desaleitamento (entre 90 e 100 dias) e do desaleitamento ao parto, respectivamente. As novilhas foram inseminadas ao alcançarem $360 \mathrm{~kg}$ de peso corporal, o que ocorreu entre 14 e 16 meses, para fêmeas

Holandesas, e entre 19 e 21 meses, para as mestiças, resultando numa previsão da idade ao primeiro parto ao redor de 23 a 25 e 28 a 30 meses, respectivamente. Os custos operacionais totais de uma fêmea bovina leiteira da raça Holandesa e mestiça foram de $\mathrm{R} \$ 3.240,28$ e $\mathrm{R} \$ 2.857,15$, respectivamente. No entanto, a idade ao primeiro parto nas fêmeas puras foi antecipada em 89 dias. Os itens com maiores representatividades no custo operacional efetivo foram a alimentação, mão-de-obra e despesas diversas, em ambos os sistemas de produção.
\end{abstract}

PALAVRAS-CHAVE: bovinocultura de leite; criação de animais; custo de produção.

\section{PRODUCTION COSTS OF DAIRY FEMALES FROM BIRTH TO FIRST CALVING}

\section{ABSTRACT}

The objective of this study was to estimate the production cost of Holstein and crossbred (Holstein-Gir) dairy heifers, in the pre and post-weaning phases and also to identify the components that have the highest influence on the final costs of the activity. In the two genetic groups, pre and post-weaning phases last from birth to weaning (between 90 to 100 days), and from weaning to calving, respectively. Heifers were bred when reached $360 \mathrm{~kg}$ of live weight, which occurred between 14 to 16 months for pure females, and from 19 to 21 months for crossbred

KEYWORDS: breeding; dairy cattle; production cost.

\section{INTRODUÇÃO}

A gestão de negócios torna o crescimento do empreendimento rural viável, fortalecendo-o para os momentos de crise, além de prepará-lo para novas oportunidades (1). Segundo Oaigen et females, resulting in an estimating age of first calving around 23 to 25 and 28 to 30 months, respectively. The total operational costs of a female Holstein and crossbred heifer were US\$1,978.24 and US\$1,700.68, respectively. However, the age at the first calving for the pure females occurred 89 days earlier. The items with highest representativeness in effective operational cost were the feeding, followed by labor and miscellaneous expenses, in both production systems.

al. (2), muitas propriedades rurais ainda são gerenciadas de forma empírica, sem condições de conhecer o custo de produção e sem considerá-los como uma das principais informações de suporte à tomada de decisão.

A criação de bezerras deve ser considerada 
como uma das principais atividades da fazenda produtora de leite, uma vez que a melhoria genética do rebanho depende do descarte de vacas velhas ou com problemas que diminuem a eficiência de produção e sua substituição por animais jovens e de potencial produtivo mais elevado. A recria é uma fase onerosa ao sistema de produção, pois, durante esse período, o produtor despende muitos recursos que poderiam ser aplicados em outra área, como, por exemplo, aquisição de tecnologias, manejo de pastagem, melhoramento genético etc. Além disso, a atividade de criação de animais de reposição ocupa uma área significativa do sistema de produção de leite.

Essa categoria animal representa a segunda maior despesa na atividade leiteira, respondendo por, aproximadamente, $20 \%$ das despesas operacionais, ficando atrás apenas da alimentação das vacas em lactação (3). Minimizar os investimentos com as novilhas, mantendo a qualidade produtiva deve ser o principal objetivo do técnico e pecuarista (4).

O gestor do sistema de produção deve conhecer os custos de produção de cada produto, seja do litro de leite, de uma novilha ao parto ou, ainda, do quilo de forragem produzido na intenção de localizar os pontos de estrangulamento e tomar as decisões para maximizar os lucros. Devido à sua importância, o centro de custo de cria e recria de fêmeas bovinas deve ser analisado separadamente da produção de leite. Para Oaigen et al. (2), a metodologia dos centros de custos se baseia no mapeamento dos centros produtivos, o que permite ao empresário rural mensurar o custo de produção por meio desses centros e verificar o impacto que determinados processos e/ou tecnologias causam ao sistema, especificamente no custo final do produto.

Apesar da relevância, poucas pesquisas sobre o levantamento do custo de produção de novilhas leiteiras têm sido realizadas, consequência da complexidade de tal tarefa. Lopes et al. (5), ao calcularem o custo operacional total até a fase de inseminação artificial $(360 \mathrm{~kg})$ da novilha, encontraram o valor de $\mathrm{R} \$ 2.040,40$ para um período de 593 dias, sendo a alimentação, aquisição de animais, depreciação, mão-de-obra e hora/máquina os itens com maior representatividade no custo operacional total. Peres et al. (6) estimaram o custo operacional total médio de R\$3.171,27 até aos 762 dias, quando os animais atingiram $350 \mathrm{~kg}$ de peso vivo; no entanto, não consideraram os custos da fase de cria. Tais pesquisadores não mencionaram a representatividade de cada item componente do custo. Guerra et al. (7) estimaram o custo operacional total de bezerras de $\mathrm{R} \$ 164,35$ (fase de cria) e novilhas mestiças de $\mathrm{R} \$ 561,21$ (recria). Porém, o valor de R\$725,56 (R\$164,35 + $\mathrm{R} \$ 561,21)$ contemplou o custo operacional total até aos 14 meses de idade das fêmeas, as quais apresentavam um peso médio de $271 \mathrm{~kg}$. Esses autores concluíram ainda que durante a fase de cria o sucedâneo foi o item com maior representatividade $(59 \%)$ no custo operacional total e, na fase de recria, o concentrado teve o maior impacto $(64 \%)$.

Diante da importância do tema e da escassez de dados publicados, objetivou-se estimar os custos de produção de fêmeas bovinas leiteiras holandesas e mestiças, nas fases de cria e recria e, ainda, identificar os componentes que exerceram maior representatividade nos custos finais da atividade.

\section{MATERIAL E MÉTODOS}

Os dados utilizados foram coletados durante um período de 12 meses, entre março de 2008 e fevereiro de 2009, em três sistemas de produção de fêmeas puras (Holandesa) e três de mestiças (Holandesa-Gir), localizados no Estado de Minas Gerais, totalizando 899 e 2.389 animais, respectivamente. Para os valores em dólar, utilizou-se a cotação de $\mathrm{R} \$ 2,16$ correspondente à data de agosto/2009. A pesquisa foi desenvolvida utilizando-se o conceito de estudo de caso, descrito por Yin (8).

Nos dois grupamentos genéticos, o estudo compreendeu o período de cria (do nascimento ao desaleitamento) e o de recria (do desaleitamento ao parto). O desaleitamento ocorreu entre $90 \mathrm{e}$ 100 dias, dependendo do critério adotado, sendo esse diferente entre os sistemas de produção estudados (peso, idade ou consumo de concentrado). As bezerras foram separadas da mãe imediatamente após a constatação do parto. Curouse o umbigo com iodo no local do parto, forneceram-se de dois a três litros de colostro e as bezerras foram alojadas em abrigos individuais, onde permaneceram até o desaleitamento, recebendo seis litros de leite, em duas refeições diárias. Os animais receberam vacinas contra botulismo, carbúnculo sintomático, leptospirose, raiva e brucelose. Após o desaleitamento, as 
bezerras foram agrupadas em lotes e as dietas formuladas de acordo com a necessidade de ganho de peso, visando atingir $80 \%$ do peso de um animal adulto ao parto. O consumo de alimentos não era mensurado em nenhuma das propriedades; no entanto, optou-se por estimá-lo em função da formulação da dieta fornecida pelo nutricionista, sendo, em média, de $2 \%$ do peso vivo, considerando uma dieta total com $65 \%$ de volumoso (silagem de milho e cana-de-açúcar) e $35 \%$ de concentrado (milho, polpa cítrica, farelo de soja, uréia e sal mineral). Devido à estrutura organizacional das fazendas, os registros dos gastos nas fases de cria e recria foram considerados como um único centro de custo, não sendo possível, portanto, nesta pesquisa, separar as duas fases. O manejo adotado foi semelhante em todas as fazendas, independentemente do grupo genético, uma vez que o técnico responsável era o mesmo. As novilhas foram inseminadas ao alcançarem $360 \mathrm{~kg}$, o que aconteceu aos 14 a 16 meses com as fêmeas puras e aos 19 a 21 meses nas fêmeas mestiças. Com isso, a idade ao primeiro parto prevista foi de 23 a 25 e 28 a 30 meses, para animais puros e mestiços, respectivamente.

Para a estimativa do custo de produção, a planilha eletrônica utilizada na análise dos dados contemplou a metodologia do custo operacional, proposta por Matsunaga et al. (9), composta pela soma do custo operacional efetivo (alimentação, mão-de-obra, sanidade, reprodução, impostos $\mathrm{e}$ taxas, energia, aluguel de máquinas e despesas diversas) e depreciações. Além desses custos, a planilha também contemplava o custo total de produção, o qual compreende a soma dos custos fixos (remuneração da terra, remuneração do capital investido, remuneração do empresário, impostos fixos e depreciação) e custo variável (alimentação, mão-de-obra, sanidade, reprodução, impostos e taxas, energia, aluguel de máquinas e despesas diversas). Os dados foram comparados por meio de análises estatísticas descritivas, utilizando-se o aplicativo MS Excel, e agrupados em tabelas objetivando-se melhor comparação, discussão e apresentação dos resultados (10).

\section{RESULTADOS E DISCUSSÃO}

Os valores médios dos totais imobilizados nos sistemas de produção com animais mestiços e puros foram de $\mathrm{R} \$ 4.296 .598,36$ e $\mathrm{R} \$ 1.364 .189,76$, respectivamente (Tabela 1). O item que teve a maior representatividade foi o "patrimônio sem considerar a terra" $(64,10 \%$ e $77,25 \%)$, seguido do valor do "patrimônio em terra", que representaram $35,90 \%$ e $22,25 \%$ do total imobilizado, para sistemas com criação de fêmeas mestiças (Holandesa-Gir) e puras, respectivamente. Essa maior porcentagem do item patrimônio em terra deve-se ao fato de a área ser bem maior nos sistemas de produção de fêmeas mestiças $(151,33$ versus 29,75 ha), além da maior taxa de lotação apresentada no sistema de fêmeas puras $(5,33$ versus 2,99 UA/ha), o que retrata a intensificação do sistema de produção na otimização dos recursos disponíveis para produção.

O valor total imobilizado por hectare pode ser utilizado como indicador de intensificação dos sistemas de produção. Esse indicador foi, em média, de R $\$ 26.994,18$, no sistema de produção de fêmeas mestiças e de $\mathrm{R} \$ 43.390,37$, no de fêmeas puras (Tabela 1). A diferença foi devido à maior área disponível para as fêmeas mestiças propiciando, assim, menor valor imobilizado por hectare. O patrimônio em benfeitorias, máquinas e equipamentos por animal foi maior nos sistemas de fêmeas puras, como consequência dessa maior intensificação do sistema de fêmeas puras, o que contribuiu para que os animais apresentassem maior ganho de peso diário $(0,454$ versus 0,481 $\mathrm{kg} / \mathrm{dia}$ ), possivelmente, por gastarem menor quantidade de energia para se locomoverem. Tal fato contribuiu para reduzir a idade ao parto das fêmeas puras (89 dias); porém com um custo total maior. Cabe ressaltar que outros fatores, como a alimentação e o próprio componente genético, também contribuem para o aumento no ganho de peso dos animais.

O valor total imobilizado por animal foi de $\mathrm{R} \$ 5.395,50$ e de $\mathrm{R} \$ 4.552,31$, nos sistemas de produção de fêmeas mestiças e puras, respectivamente (Tabela 1). Apesar do maior valor imobilizado por hectare apresentado pelo sistema com fêmeas puras, quando o valor da variável é diluído por unidade produtiva, ele se torna menor em virtude da maior taxa de lotação desse sistema, ou seja, otimizaram-se os fatores de produção, principalmente $o$ item terra. Os indicadores "imobilizado por hectare" e "imobilizado por animal" podem ser utilizados como parâmetros na implantação de um sistema de produção, quando na ausência de um projeto de viabilidade econômica, desde que o sistema de referência tenha apresentado um resultado positivo. Cabe ressaltar que tal inferência deve ser feita apenas 
para sistemas que apresentem a mesma

produtividade esperada.

Tabela 1 - Recursos disponíveis nos centros de custos cria e recria de fêmeas mestiças e puras destinadas à reposição de matrizes leiteiras

\begin{tabular}{lllll}
\hline & \multicolumn{2}{l}{ Fêmeas mestiças } & \multicolumn{2}{l}{ Fêmeas puras } \\
\cline { 2 - 5 } Especificação & Média & DP & Média & DP \\
\hline Patrimônio em terra (R\$) & $1.542 .666,67$ & $1.705 .274,56$ & $303.500,00$ & $150.302,20$ \\
Patrimônio sem terra (R\$) & $2.753 .931,70$ & $3.419 .604,54$ & $1.060 .689,76$ & $675.882,99$ \\
$\quad$ Valor em benfeitorias (R\$) & $55.910,00$ & $50.179,25$ & $19.310,25$ & $12.787,38$ \\
$\quad$ Valor em máquinas (R\$) & $13.055,33$ & $17.121,60$ & $5.644,82$ & $3.933,39$ \\
$\quad$ Valor em equipamentos e implementos (R\$) & $21.133,03$ & $31.956,58$ & $9.734,70$ & $6.278,82$ \\
$\quad$ Valor em animais (R\$) & $2.663 .833,33$ & $3.321 .283,88$ & $1.026 .000,00$ & $653.110,06$ \\
Área (ha) & 151,33 & 172,06 & 29,75 & 13,34 \\
Quantidade de animais (cab.) & 796,33 & 918,10 & 299,67 & 177,51 \\
Quantidade de mão-de-obra (homem/dia) & 4,00 & 1,00 & 3,67 & 0,58 \\
Total imobilizado (R\$) & $4.296 .598,36$ & $5.105 .616,89$ & $1.364 .189,76$ & $823.306,13$ \\
Total imobilizado por ha (R\$) & $26.994,18$ & $1.870,96$ & $43.390,37$ & $10.167,65$ \\
Total imobilizado por animal (R\$) & $5.395,50$ & 980,21 & $4.552,31$ & 315,67 \\
\hline DP=Ding
\end{tabular}

$\mathrm{DP}=$ Desvio-padrão

O custo operacional total foi $29,5 \%$ maior para as fêmeas puras (Tabela 2). Os fatores que contribuíram para isso foram, principalmente, a maior despesa com alimentação e sanidade. Cabe ressaltar que esse maior "investimento" em alimentação e sanidade contribuiu para que o sistema de fêmeas puras tivesse uma idade ao primeiro parto 89 dias inferior ao de fêmeas mestiças, com uma diferença no custo operacional total de $\mathrm{R} \$ 871,49$ $(\mathrm{R} \$ 2.078,49$ - $\mathrm{R} \$ 2.949,98)$. Essa menor idade ao parto antecipará a receita adicional com a venda de leite, reduzindo o tempo de retorno do capital. Tal fato é de grande importância em sistemas de produção em que o ponto de equilíbrio do sistema de produção de leite ainda não foi atingido. Sistemas nessas condições necessitam aumentar o volume de leite diário produzido, para "diluir" os custos fixos. Se o custo operacional total da produção de leite for inferior ao preço de venda, isso implicará no aumento da rentabilidade do sistema de produção. Para reduzir o custo ao primeiro parto, algumas alternativas são diminuir a idade ao primeiro parto, desde que não se aumente o custo diário, reduzir o custo diário, sem aumentar a idade ao primeiro parto e/ou aumentar a taxa de lotação.

A depreciação foi mais representativa na cria e recria de fêmeas mestiças do que de fêmeas puras (Tabela 2), representando $3,48 \%$ e $1,02 \%$ do custo operacional total, respectivamente. No entanto, a representatividade do "patrimônio sem considerar a terra" foi maior nos sistemas de produção de fêmeas puras $(77,25$ versus $64,10 \%)$. A explicação para a depreciação representar mais onde o "patrimônio sem considerar a terra" teve menor representação é pelo fato do custo operacional efetivo das fêmeas puras ter sido bem maior do que o das fêmeas mestiças ( $R$ \$2.919,80 versus $R \$ 2.006,14)$; assim, a representação da depreciação no custo operacional total foi menor. Os valores encontrados para a representatividade da depreciação neste estudo são inferiores aos $15 \%$ obtidos por Lopes et al. (5), embora tais pesquisadores tenham estimado o custo apenas até a idade à primeira cobertura e não ao primeiro parto. De acordo com Lopes et al. (10), quanto menor o impacto da depreciação no custo operacional total, maior é a eficiência de utilização da infraestrutura (bens depreciáveis). Outras possibilidades para sistemas com pouca depreciação podem ser bens obsoletos, falta de recurso para produção ou, ainda, elevado custo operacional efetivo.

Os custos fixos foram maiores nos sistemas de produção de fêmeas mestiças, principalmente em função da maior remuneração do capital investido e da remuneração da terra. A "diluição" de custos fixos, como a depreciação, é atingida com o aumento da escala de produção (10). Observou-se que as mestiças apresentaram custo total diário menor do 
que as puras ( $\mathrm{R} \$ 3,12$ versus $\mathrm{R} \$ 3,93)$ (Tabela 2$)$ e, sistemas de produção se localizavam em regiões consequentemente, um animal mais barato ao parto $(\mathrm{R} \$ 2.857,15$ versus $\mathrm{R} \$ 3.240,28)$. Uma vez que os diferentes, as características e custos de insumos também eram diferentes.

Tabela 2 - Custo de produção de fêmeas mestiças e puras ao primeiro parto, em R\$ e U\$\$, e desempenho animal

\begin{tabular}{|c|c|c|c|c|}
\hline \multirow[b]{2}{*}{ Especificação } & \multicolumn{2}{|c|}{ Fêmeas mestiças } & \multicolumn{2}{|c|}{ Fêmeas puras } \\
\hline & Média & $\mathrm{DP}$ & Média & DP \\
\hline Custo operacional total (COT) & $2.078,49$ & 496,49 & $2.949,98$ & $1.153,06$ \\
\hline Custo operacional efetivo (COE) & $2.006,14$ & 494,32 & $2.919,80$ & $1.140,74$ \\
\hline Depreciação & 72,35 & 12,17 & 30,18 & 13,57 \\
\hline Custo total (CT) & $2.857,15$ & 287,09 & $3.240,28$ & $1.151,77$ \\
\hline Custo fixo (CF) & 744,52 & 468,12 & 158,29 & 31,18 \\
\hline Remuneração da terra & 218,25 & 45,08 & 105,5 & 19 \\
\hline Remuneração do cap. Investido & 450,44 & 493,95 & 52,03 & 8,1 \\
\hline Impostos fixos & 3,43 & 3,95 & 10,13 & 9,75 \\
\hline Depreciação & 72,35 & 12,17 & 30,18 & 13,57 \\
\hline Custo variável (CV) & $2.112,62$ & 470,42 & $3.081,99$ & $1.137,67$ \\
\hline Custo operac. efetivo (s/impostos) & $2.002,71$ & 490,58 & $2.909,67$ & $1.136,40$ \\
\hline \multirow[t]{2}{*}{ Remuneração do capital de giro } & 109,91 & 25,52 & 172,32 & 6,27 \\
\hline & \multicolumn{4}{|c|}{$\mathrm{R} \$$ /animal/dia } \\
\hline Custo operacional total & 2,27 & 0,54 & 3,57 & 1,55 \\
\hline Custo operacional efetivo & 2,19 & 0,54 & 3,54 & 1,54 \\
\hline Custo total & 3,12 & 0,31 & 3,93 & 1,56 \\
\hline Custo fixo & 0,81 & 0,51 & 0,19 & 0,04 \\
\hline \multirow[t]{2}{*}{ Custo variável } & 2,31 & 0,51 & 3,73 & 1,53 \\
\hline & \multicolumn{4}{|c|}{ R\$/animal ao primeiro parto } \\
\hline Custo operacional total & $2.078,49$ & 488,44 & $2.949,98$ & $1.123,47$ \\
\hline Custo operacional efetivo & $2.006,14$ & 494,32 & $2.919,80$ & $1.140,74$ \\
\hline Custo total & $2.857,15$ & 353,66 & $3.240,28$ & $1.067,70$ \\
\hline Custo fixo & 744,52 & 470,36 & 158,29 & 76,6 \\
\hline \multirow[t]{2}{*}{ Custo variável } & $2.112,62$ & 470,42 & $3.081,99$ & $1.137,67$ \\
\hline & \multicolumn{4}{|c|}{ U\$\$/animal ao primeiro parto* } \\
\hline Custo operacional total & 962,26 & 226,13 & $1.365,73$ & 520,13 \\
\hline Custo operacional efetivo & 928,77 & 228,85 & $1.351,76$ & 528,12 \\
\hline Custo total & $1.322,75$ & 163,73 & $1.500,13$ & 494,31 \\
\hline Custo fixo & 344,69 & 217,76 & 73,28 & 35,46 \\
\hline \multirow[t]{2}{*}{ Custo variável } & 978,06 & 217,79 & $1.426,85$ & 526,7 \\
\hline & \multicolumn{4}{|c|}{$\mathrm{R} \$ / \mathrm{kg}$ de peso vivo } \\
\hline Custo operacional total & 4,99 & 1,21 & 7,42 & 2,81 \\
\hline Custo operacional efetivo & 4,95 & 1,22 & 7,3 & 2,85 \\
\hline Custo total & 5,71 & 1,31 & 7,83 & 2,82 \\
\hline Custo fixo & 0,75 & 0,11 & 0,54 & 0,06 \\
\hline \multirow[t]{2}{*}{ Custo variável } & 4,96 & 1,21 & 7,29 & 2,85 \\
\hline & \multicolumn{4}{|c|}{ Desempenho animal } \\
\hline Idade ao primeiro parto (dia) & 915,63 & 34,5 & 825,32 & 45,4 \\
\hline Peso ao parto $(\mathrm{kg})$ & 416,53 & 23,3 & 397,57 & 89,2 \\
\hline Ganho de peso diário $(\mathrm{kg} / \mathrm{dia})$ & 0,454 & 0,22 & 0,481 & 0,34 \\
\hline
\end{tabular}

$\mathrm{Dp}=$ Desvio padrão * Dólar $=\mathrm{R} \$ 2,16$ (agosto/2009)

Uma das utilidades de se estimar o custo de produção de novilhas ao parto é compará-lo com o preço de mercado para tomar a decisão de criar, comprar ou terceirizar a criação desses animais (10). Cada uma das decisões tem suas vantagens $\mathrm{e}$ limitações. A compra, muitas vezes, não permite conhecer os ancestrais, bem como o histórico sanitário da novilha; porém, dependendo da região, podem ser encontrados animais com preços mais baixos. Com relação à terceirização, o animal pertence à fazenda, ou seja, sabe-se a genealogia; normalmente, há um funcionário especializado no manejo das bezerras e é disponibilizada área para agricultura e/ou produção de leite. Os agravantes são 
o contato com animais de outras propriedades, que permite a transmissão de doenças, e a distância a ser percorrida até o local onde serão realizadas a cria e recria, que pode inviabilizar o processo.

Um levantamento americano (11) a respeito da terceirização da criação de animais jovens (cria e recria) concluiu que menos de $5 \%$ das pequenas fazendas leiteiras terceiriza a criação de suas novilhas, em comparação aos $46,0 \%$ das grandes; metade das fazendas $(50,1 \%)$ enviam bezerras ainda em aleitamento, logo após o período de colostragem; cerca de dois terços $(67,6 \%)$ recebem essas novilhas já prenhes, com idade média de 21,6 meses, de volta à fazenda e $36,2 \%$ dos produtores enviam seus animais para fazendas nas quais eles não tenham contato com bovinos provenientes de outras fazendas. Gabler et al. (12), comparando o custo de produção e o desempenho de novilhas criadas na própria fazenda ou terceirizadas, concluíram que o custo operacional total médio de produção foi de US\$1.124,06 e US\$1.019,20, respectivamente; e a idade ao parto das novilhas de 24,13 e 22,75 meses, para as novilhas que foram recriadas no próprio sistema de produção ou terceirizadas, respectivamente. No entanto, a comparação de desempenho na primeira lactação e a existência de problemas sanitários não foram avaliados nesses estudos.

$\mathrm{O}$ custo operacional efetivo diário encontrado no sistema de fêmeas puras ( $R \$ 3,54$; US $\$ 1,90$ ) foi menor que o obtido por Lopes et al. (5) (R\$4,06; US\$2,18), ao estudarem o custo de produção de fêmeas puras da raça Holandesa, no sul de Minas Gerais, do nascimento à primeira cobertura. Tal diferença pode ser atribuída à maior eficiência de produção do presente estudo.

A alimentação representou 58,49\% e 55,69\% dos custos, nos sistemas de produção de fêmeas mestiças e puras, respectivamente, sendo o concentrado energético e a forragem os itens com a maior diferença entre os sistemas (Tabela 3). No entanto, o gasto efetivo com alimentação por animal foi maior no sistema de fêmeas puras ( $\mathrm{R} \$ 1.173,39$ versus $\mathrm{R} \$ 1.626,04)$, o que justifica o maior custo operacional efetivo neste sistema. Segundo Lopes et al. (10), a porcentagem de cada item na composição do custo é de fundamental importância para o gestor visualizar os itens com maior representatividade e concentrar maiores esforços na tentativa de redução de custos e, consequentemente, aumentar a rentabilidade. Dois fatores determinaram a maior representatividade do item "forragem" no custo operacional efetivo das fêmeas mestiças: a ineficiência de produção de forragem em um dos sistemas de produção e a maior utilização de fibra efetiva proveniente dos subprodutos, diminuindo, assim, a necessidade de forragem nos sistemas de produção de fêmeas puras. Outros pesquisadores (5, 12) verificaram que os custos com alimentação variaram de $46,63 \%$ a $64 \%$; no entanto, a duração dos estudos foram diferentes.

A forragem representou, em média, 15,81\% e $8,96 \%$ dos custos, nos sistemas de produção de fêmeas mestiças e puras, respectivamente (Tabela 3). Alguns fatores podem ter afetado tais resultados, entre eles: necessidade de maior utilização da forrageira de inverno, em virtude de escassez de pastagem; maior utilização de subprodutos fibrosos; custo da forrageira de inverno mais elevado, menor produtividade da forrageira de inverno, entre outros.

As despesas com o uso de minerais/aditivos foi mais acentuada nos sistemas com fêmeas puras $(10,29 \%)$, se comparado aos sistemas de mestiças $(2,43 \%)$ (Tabela 3$)$. Tal fato pode ter ocorrido em função de uma dieta mais ajustada, com maior inclusão de minerais, uso de produtos de maior valor comercial ou, ainda, uso incorreto de minerais.

As despesas com o alimento leite, destinado ao aleitamento das bezerras, representou $11,76 \%$ $(\mathrm{R} \$ 235,91)$ e $6,12 \%(\mathrm{R} \$ 178,69)$ dos custos nos sistemas de produção de fêmeas mestiças e puras, respectivamente. O principal motivo desta menor representatividade foi o menor período médio de aleitamento nos sistemas de produção de fêmeas puras ( 80 versus 95 dias) e a utilização de sucedâneo em um dos sistemas. $\mathrm{O}$ uso de sucedâneos pode ser uma alternativa interessante em sistemas nos quais as bezerras em aleitamento ficam localizadas distante do centro produtivo de leite ou, ainda, em momento em que o preço do leite esteja elevado. Caberá ao técnico fazer uma análise criteriosa, antes de tomar a decisão de utilizar ou não o sucedâneo.

$\mathrm{O}$ item mão-de-obra foi o segundo item mais representativo no custo operacional efetivo, sendo maior no grupo de fêmeas mestiças (Tabela 3). Observa-se que o sub-item assistência técnica representou 4,99 e 4,90\% do custo operacional efetivo nos sistemas de fêmeas mestiças e puras, respectivamente. Uma maneira de otimizar a representatividade com a mão-de-obra é conseguindo uma economia de escala, ou seja, aumentar a quantidade de animais com o mesmo número de funcionários, desde que as condições básicas de trabalho sejam mantidas.

As despesas com sanidade e a reprodução foram os itens que mais se diferenciaram entre os dois sistemas de produção. No que diz respeito à sanidade, a diferença pode ter sido em função da rusticidade dos animais do grupo genético mestiço, já a maior despesa com reprodução foi devido às tecnologias (IATF e sêmen sexado) utilizadas para as fêmeas puras. 
As despesas com aluguel de máquinas, utilizadas para arraçoar os animais, representaram $3,16 \%$ e $4,06 \%$ do custo operacional efetivo dos sistemas de criação de fêmeas mestiças e puras, respectivamente. Lopes et al. (5) encontraram valor superior $(13,55 \%)$ provavelmente em função da diferença na quantidade de animais entre os estudos: 37 (5) versus 796 mestiças e 299 puras, mostrando a importância da escala de produção. No presente estudo observou-se maior eficiência de utilização das máquinas alugadas.

Tabela 3 - Representatividade de cada item no custo operacional efetivo no centro de custo cria e recria de fêmeas mestiças e puras, ao primeiro parto, em porcentagem, durante o período de março de 2008 a fevereiro de 2009

\begin{tabular}{|c|c|c|c|c|}
\hline \multirow[b]{2}{*}{ Especificação } & \multicolumn{2}{|c|}{ Fêmeas mestiças } & \multicolumn{2}{|c|}{ Fêmeas puras } \\
\hline & Média & DP & Média & DP \\
\hline Alimentação & 58,49 & 6,54 & 55,69 & 11,40 \\
\hline Concentrado proteico & 12,21 & 3,04 & 14,42 & 3,78 \\
\hline Concentrado energético & 16,28 & 9,00 & 5,89 & 2,62 \\
\hline Minerais/aditivos & 2,43 & 0,99 & 10,29 & 11,42 \\
\hline Forragem & 15,81 & 7,78 & 8,96 & 3,91 \\
\hline Leite & 11,76 & 7,23 & 6,12 & 1,76 \\
\hline Mão-de-obra & 18,96 & 4,94 & 16,58 & 9,56 \\
\hline Salário & 11,63 & 1,50 & 9,47 & 4,73 \\
\hline Encargos & 0,90 & 0,82 & 1,15 & 0,69 \\
\hline EPI/Uniforme & 0,14 & 0,07 & 0,25 & 0,19 \\
\hline Diarista & 0,76 & 0,89 & 0,47 & 0,47 \\
\hline Assistência técnica & 4,99 & 3,06 & 4,90 & 3,43 \\
\hline Mão-de-obra de terceiros & 0,54 & 0,47 & 0,35 & 0,34 \\
\hline Sanidade & 3,69 & 1,74 & 5,46 & 3,31 \\
\hline Reprodução & 1,89 & 0,65 & 6,96 & 4,67 \\
\hline Insumos reprodução & 1,70 & 0,60 & 4,81 & 3,15 \\
\hline Hormônios & 0,19 & 0,10 & 2,15 & 3,41 \\
\hline Impostos e taxas & 0,27 & 0,25 & 0,51 & 0,33 \\
\hline Energia & 2,12 & 0,29 & 1,74 & 2,16 \\
\hline Energia elétrica & 1,92 & 0,43 & 0,41 & 0,34 \\
\hline Combustível e lubrificante & 0,20 & 0,26 & 1,33 & 1,90 \\
\hline Aluguel máquinas & 3,16 & 0,50 & 4,06 & 0,65 \\
\hline Despesas diversas & 11,41 & 5,75 & 8,99 & 2,86 \\
\hline Despesas administrativas & 5,76 & 5,10 & 4,50 & 5,26 \\
\hline Manejo de animais & 0,52 & 0,49 & 0,29 & 0,05 \\
\hline Manutenção de benfeitorias & 1,31 & 0,94 & 0,85 & 1,46 \\
\hline Frete & 0,83 & 1,21 & 0,19 & 0,32 \\
\hline Telefone & 0,56 & 0,72 & 0,15 & 0,21 \\
\hline Outros & 2,42 & 0,65 & 0,45 & 0,39 \\
\hline
\end{tabular}

$\mathrm{DP}=$ desvio padrão

As proporções de fêmeas para reposição, em relação ao total de animais do rebanho, foram de $53,85 \%$ e $46,37 \%$, no centro de custo cria e recria de fêmeas mestiças e puras, respectivamente. Essa maior proporção no sistema de fêmeas mestiças foi devido à idade ao primeiro parto mais avançada (915 versus 825,23 dias) e à maior comercialização de animais, por um dos sistemas de fêmeas mestiças, o 
que exigiu maior quantidade de animais para reposição.

As taxas de ocupação (área de pastagem e plantio de milho mais área de cocho e manejo) foram de 2,99 e 5,33 UA/ha, para os sistemas de produção de fêmeas mestiças e puras, respectivamente. A menor taxa de ocupação foi principalmente devido às fêmeas mestiças permanecerem em sistema de pasto e as puras serem mais confinadas e mais dependentes de silagem de milho e concentrado.

A relação custo fixo/custo total foi maior nos sistemas de produção de fêmeas mestiças $(16,88$ versus $4,89 \%$ ) em função da maior área, o que aumentou a contribuição do item remuneração da terra. Tal indicador serve para medir a eficiência da utilização dos recursos disponíveis. Sendo assim, pode-se considerar que os sistemas com fêmeas puras apresentaram maior eficiência de utilização de tais recursos. A relação custo variável/custo total teve menor representação nos sistemas com fêmeas mestiças $(83,12 \%$ versus $95,11 \%)$, e a depreciação em relação ao custo total foi de 3,48\% e $1,02 \%$, respectivamente. Isso mostra que, nos sistemas com fêmeas puras, as despesas operacionais tiveram grande influência na composição do custo total de produção. Essa constatação evidencia que os gestores dos sistemas com fêmeas puras devem dar maior atenção às despesas operacionais, seja na redução de uso dos insumos e ou na compra mais eficiente dos mesmos. Por outro lado, nos sistemas de fêmeas mestiças, o aumento da taxa de lotação deve ser buscado para que possa ocorrer uma "diluição" dos custos fixos, por exemplo, reduzindo a área destinada a esse sistema ou aumentando a quantidade de animais.

\section{CONCLUSÕES}

Os custos totais de produção de uma fêmea bovina leiteira holandesa e mestiça foram de $\mathrm{R} \$ 3.240,28$ e $\mathrm{R} \$ 2.857,15$, respectivamente. No entanto, a idade ao primeiro parto nas fêmeas puras foi antecipada em 89 dias. Os itens com maior representatividade no custo operacional efetivo foram a alimentação, mão-de-obra e despesas diversas, em ambos os sistemas de produção. Nesses sistemas de produção, os gestores devem dedicar maior atenção no custo variável dos sistemas de fêmeas puras e no custo fixo dos sistemas de produção de fêmeas mestiças.

\section{REFERÊNCIAS}

1. Oaigen RP, Barcellos JOJ, Christofari LF. Custos de produção em terneiros de corte: uma revisão. [Production cost of the beef calves: a review] Veterinária em Foco. [Internet] 2006:3(2):169-180. Available from: http://www.ulbra.br/medicinaveterinaria/files/revista_v3 n 2 .pdf Portuguese.

2. Oaigen RP, Barcellos JOJ, Christofari LF, Neto JB, Oliveira TE, Prates ER. Melhoria organizacional na produção de bezerros de corte a partir dos centros de custos. [Organizational improvement in the beef calves production from of the cost centers] Revista Brasileira de Zootecnia. [Internet] 2008:37(7)580-87. Available from: http://www.scielo.br/scielo.php?script=sci_arttext\&pid=S $1516-35982008000300025 \& \operatorname{lng}=\% 20 \mathrm{en} \& n \mathrm{~nm}=$ iso Portuguese.

3. Heinrichs AJ. Raising dairy replacements to meet the needs of the 21st century. Journal Dairy Science. [Internet] 1993:76(10):3179-87. Available from: http://download.journals.elsevierhealth.com/pdfs/journals/ 0022-0302/PIIS002203029377656 0.pdf

4. Hoffman PC, Funk DA. Applied dynamics of dairy replacement growth and management. Journal Dairy Science. [Internet] 1992:75(9):2504-16. Available from: http://download.journals.elsevierhealth.com/pdfs/journals/ 0022-0302/PIIS002203029278 0126.pdf

5. Lopes MA, Franco Neto A, Santos G, Demeu FA, Lopes LMF, Rezende SM. Custos de produção de fêmeas bovinas da raça holandesa nas fases de cria e recria em um sistema de produção de leite no sul de Minas Gerais.[ Production costs of bovine females of Holstein breed in the pre and post weaning phases in a milk production system at Southern Minas Gerais] Boletim de Indústria Animal. [Internet] 2010:67(1):9-15. Available from: http://www.iz.sp.gov.br/pdfsbia/1287401869.pdf Portuguese.

6. Peres AAC, Souza PM, Vasquez HM, Silva JFC, Haddades IR, Lista FN. Custos de produção na recria de novilhas mestiças holandês-zebu em pastagem de capimelefante. [Production costs of growing holstein-zebu heifers in elephantgrass pasture] Boletim da Indústria animal. [Internet] 2008:65(2):99-05. Available from: http://www.iz.sp.gov.br/pdfsbia/1216213909.pdf Portuguese.

7. Guerra MG, Guilhermino MM, Nascimento AH, Medeiros RHR, Lima Júnior DM. Custo operacional total na cria e recria de bovinos leiteiros. [Total operating cost in the rearing of dairy cattle]. Revista verde de agroecologia e desenvolvimento sustentável. [Internet] 2010:5(3):172-178. Available from: http://www.gvaa.com.br/revista/index.php/RVADS Portuguese.

8. Yin RK. Case study research: design and methods. Rev. ed. Newbury Park: Sage; 1989. 145p. Disponível em: http://designstudiesdiscourses.files.wordpress.com/2013/0 9/yincasestudy.pdf

9. Matsunaga M, Bemelmans PF, Toledo PEN, Dulley RD, Okawa H, Pedroso IA. Metodologia de custo de produção utilizado pelo IEA. Boletim do Instituo de Economia Agrícola. 1976:23(1):123-39 
10. Lopes MA, Lima ALR, Carvalho FM, Reis RP, Santos IS, Saraiva FH. Controle gerencial e estudo da rentabilidade de sistemas de produção de leite na região de Lavras (MG). [Managerial control and profitability study of milk production systems in Lavras region (MG)] Ciência e Agrotecnologia. [Internet] 2004:28(4):883-92. Available from: http://www.scielo.br/pdf/cagro/v28n4/22.pdf Portuguese.

11. USDA. Heifer Calf Health and Management Practices on U.S. Dairy Operations. USDA:APHIS:VS [Internet]. 2010; 1:[1-64 pp.]. Available from: http://nahms.aphis.usda.gov

12. Gabler MT, Tozer PR, Heinrichs JA. Development of a cost analysis spreadsheet for calculating the costs to raise a replacement dairy heifer. Journal of Dairy Science. [Internet] 2000:83(5): 1104-09. Available from: http://download.journals.elsevierhealth.com/pdfs/journals/ 0022-0302/PIIS0022030200 749757.pdf

Protocolado em: 09 jun. 2011. Aceito em: 22 out. 2013 